\title{
Controlled trial of azathioprine in treatment of steroid-responsive nephrotic syndrome of childhood
}

\author{
T. M. BARRATT, J. S. CAMERON, C. CHANTLER, R. COUNAHAN, C. S. OGG, AND \\ J. F. SOOTHILL
}

From the Renal Unit, The Hospital for Sick Children; Department of Immunology, Institute of Child Health; and Evelina Children's Department and Renal Unit, Department of Medicine, Guy's Hospital, London

SUMMARY A controlled trial of azathioprine treatment of steroid-responsive frequent-relapsing nephrotic syndrome of childhood failed to show a therapeutic effect on the stability of remission after withdrawal of corticosteroid treatment.

Cyclophosphamide has been shown to be effective in preventing relapse of steroid-responsive nephrotic syndrome of childhood (Barratt and Soothill, 1970). However, a similar significant effect was not observed by Abramowicz et al. (1970), in a doubleblind trial of azathioprine. This drug was administered in a dosage of $60 \mathrm{mg} / \mathrm{m}^{2}$ surface area per day for 6 months to steroid-responsive nephrotic children, maintained on intermittent prednisone. This study did show, however, that there was a nonsignificant trend toward fewer relapses in the treated group.

We thought that their use of intermittent prednisone militated against detection of a therapeutic effect of azathioprine because of the low rate of relapse in the placebo group. In view of the anxiety about the side effects of cyclophosphamide (Fairley, et al., 1972), we felt that it was necessary to re-examine the possibility that azathioprine might enhance the stability of remission in those patients.

\section{Patients and methods}

Diagnostic criteria and definitions have been previously published (Barratt and Soothill, 1970). Albumin was measured immunochemically and its excretion in random urine samples was expressed as the albumin/creatinine concentration ratio $(\mathrm{Ua} / \mathrm{Uc})$ (Barratt, et al., 1970).

Children under 14 years of age with steroidresponsive frequent-relapsing nephrotic syndrome who had previously relapsed on at least $0.2 \mathrm{mg} / \mathrm{kg}$ body weight of prednisolone on alternate days were included in the trial when they had been in prednisolone-maintained remission for at least 2 weeks. Some of the children who had previously been

Received 20 September 1976 treated with cyclophosphamide were allocated separately.

\section{Trial design}

Treatment regimens. The children in a prednisolonemaintained remission were randomly allocated to one of two groups, A or B. All received the maintenance prednisolone for the first 8 weeks, which was then withdrawn in a standardized approximately logarithmic manner during weeks 9-16. Group B also received azathioprine $2 \mathrm{mg} / \mathrm{kg}$ body weight per day (ideal weight for height) as a single daily dose during weeks 1-8. All were treated at home. Haemoglobin, differential white blood cell count, and platelet count were measured weekly during the period of azathioprine therapy and none was abnormal.

Determination of relapse. The parents tested the urine daily with Albustix and reported to hospital if a $2+$ reaction was observed for 2 days. Two urine specimens were then obtained for estimation of $\mathrm{Ua} / \mathrm{Uc}$ to confirm the relapse. In addition, $\mathrm{Ua} / \mathrm{Uc}$ estimations were performed on random urine samples in weeks 8,16 , and 32 . Children were classified as relapsing if criteria of relapse was observed on or before week 32 .

Statistical design. We intended to study 32 patients, allocating separately 16 who had not received cyclophosphamide and 16 who had, using 2 boxes containing 8 cards for each group. We planned to analyse the data by Exact Test $(2 \times 2$ contingency tables; Finney et al., 1963) twice, after the first 16 and then all 32 cases reached week 32 . The null hypothesis was that there were not more relapses in group A than in group B: a predetermined signi- 


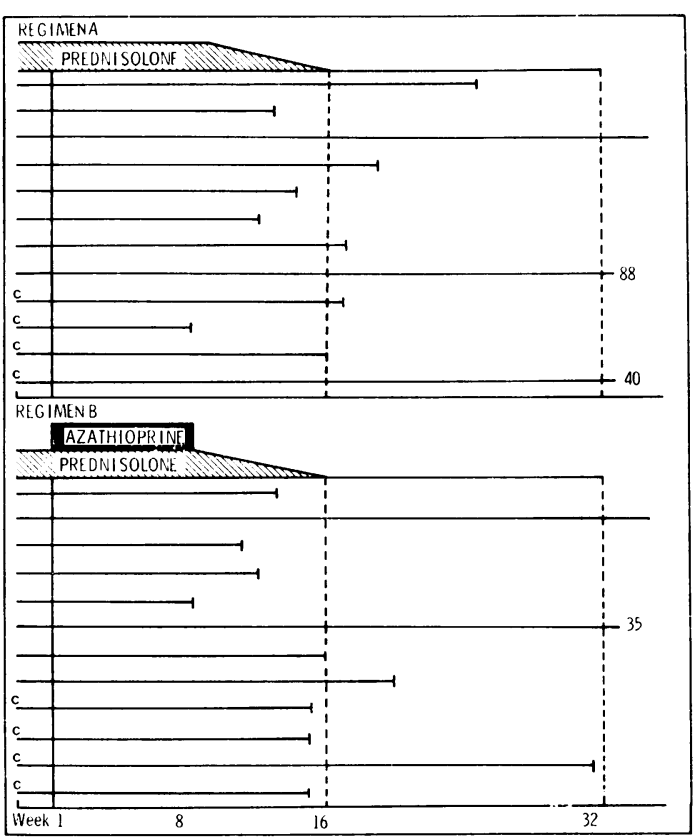

Fig. Time to relapse (weeks) in 24 children with steroid-responsive frequently relapsing nephrotic syndrome, allocated to two groups. Group $A$ received only prednisolone and group $B$ azathioprine too. $C$ represents patients who had previously received cyclophosphamide. 2 children were still in remission 120 weeks after entry into the trial.

ficance level for this one-sided trial was set at $5 \%$ $(\alpha=0.05$,$) and the technique of Armitage et al.,$ (1969) for assessing repeated significance tests on accumulating data was applied, such as that at each of the two analyses $\alpha=0.030$. However, at the time that we chose to end the trial, only 24 patients had been entered of whom 4 in each group had previously received cyclophosphamide.

\section{Results}

At the first analysis point, after 16 children had reached week 32, 6 of the 8 controls and 7 of the 8 azathioprine-treated patients had relapsed. After 24 children reached this point, 9 of the 12 controls and 10 of the 12 azathioprine-treated patients had relapsed. The median week of relapse in the controls was 17 and in the azathioprine-treated group 15; this difference was not significant on the Rank-sum test.

We then considered what the position would be if of the remaining 8 children all the controls relapsed and all the treated patients remained in remission. Even if that had happened, the difference of fre- quency of relapse in the two groups would not have been significant, so the trial was stopped.

\section{Discussion}

Our data are similar to those of Abramowicz et al. (1970) and fail to show a therapeutic effect of azathioprine in preventing relapse of steroid-responsive nephrotic syndrome. It is of interest that cyclophosphamide should be effective and azathioprine not, since both drugs have immunosuppressive characteristics; but they act in different ways, cyclophosphamide being an alkylating agent and azathioprine an antimetabolite. There is now considerable evidence that this disease has an immune basis (Thomson et al., 1976) but the mechanism of damage is not known and so the effect of cyclophosphamide may not be immunosuppressive. Another possibility is that the dose or duration of azathioprine therapy was inadequate. But at doses of azathioprine greater than $2.5 \mathrm{mg} / \mathrm{kg}$ per day dose-related toxicity becomes apparent, the most serious being thrombocytopenia and a reduced white cell count. Our study provides no support for a change from cyclophosphamide to azathioprine to avoid the risk of gonadal toxicity reported for cyclophosphamide (Fairley et al., 1972).

We thank the Department of Haematology, The Hospital for Sick Children, for the blood counts, and Miss F. C. Rose for technical assistance.

\section{References}

Abramowicz, M., Arneil, G. C., Barnett, H. L. Barron, B. A., Edelmann, C. M., Gordillo, P. G., Greifer, I. Hallman, N., Kobayashi, O., and Tiddens, H. A. (1970). Controlled trial of azathioprine in children with nephrotic syndrome. Lancet, 1, 959-961.

Armitage, P., McPherson, C. K., and Rowe, B. C. (1969). Repeated significance tests on accumulating data. Journal of the Royal Statistical Society. Series A (General), 132, 235-244.

Barratt, T. M., and Soothill, J. F. (1970). Controlled trial of cyclophosphamide in steroid sensitive relapsing nephrotic syndrome of childhood. Lancet, 2, 479-482.

Barratt, T. M., McLaine, P. N., and Soothill, J. F. (1970). Albumin excretion as a measure of glomerular dysfunction in children. Archives of Disease in Childhood, 45, 496-501.

Fairley, K. F., Barrie, J. U., and Johnson, W. (1972). Sterility and testicular atrophy related to cyclophosphamide therapy. Lancet, 1, 568-569.

Finney, D. J., Latscha, R., Bennett. B. N., and Hsu, P. (1963). Tables for Testing Significance in $2 \times 2$ Contingency Table. Cambridge University Press, London.

Thomson, P., Barratt, T. M., Stokes, C. R., Turner, M. W., and Soothill, J. F. (1976). HLA-typing and atopic features in steroid-responsive nephrotic syndrome of childhood. Lancet, 2, 765-768.

Correspondence to Dr. T. M. Barratt, Department of Immunology, Institute of Child Health, 30 Guilford Street, London WC1N 1EH. 